\title{
Modulating Hippocampal Plasticity with In Vivo Brain Stimulation
}

\author{
DDoyce G. Rohan, ${ }^{1,3}$ Kim A. Carhuatanta, ${ }^{2}$ Shawn M. McInturf, ${ }^{1}$ Molly K. Miklasevich, ${ }^{1,4}$ and Ryan Jankord ${ }^{2}$ \\ ${ }^{1}$ Naval Medical Research Unit Dayton, Environmental Health Effects Directorate and ${ }^{2}$ Air Force Research Laboratory, 711th Human Performance Wing, \\ Wright Patterson Air Force Base, Ohio 45433, ${ }^{3}$ Oak Ridge Institute for Science and Education, Oak Ridge, Tennessee 37831 , and ${ }^{4}$ CAMRIS International, \\ Bethesda, Maryland 20814
}

Investigations into the use of transcranial direct current stimulation (tDCS) in relieving symptoms of neurological disorders and enhancing cognitive or motor performance have exhibited promising results. However, the mechanisms by which tDCS effects brain function remain under scrutiny. We have demonstrated that in vivo tDCS in rats produced a lasting effect on hippocampal synaptic plasticity, as measured using extracellular recordings. Ex vivo preparations of hippocampal slices from rats that have been subjected to tDCS of 0.10 or $0.25 \mathrm{~mA}$ for $30 \mathrm{~min}$ followed by $30 \mathrm{~min}$ of recovery time displayed a robust twofold enhancement in long-term potentiation (LTP) induction accompanied by a $30 \%$ increase in paired-pulse facilitation (PPF). The magnitude of the LTP effect was greater with $0.25 \mathrm{~mA}$ compared with $0.10 \mathrm{~mA}$ stimulations, suggesting a dose-dependent relationship between tDCS intensity and its effect on synaptic plasticity. To test the persistence of these observed effects, animals were stimulated in vivo for $30 \mathrm{~min}$ at $0.25 \mathrm{~mA}$ and then allowed to return to their home cage for $24 \mathrm{~h}$. Observation of the enhanced LTP induction, but not the enhanced PPF, continued $24 \mathrm{~h}$ after completion of $0.25 \mathrm{~mA}$ of tDCS. Addition of the NMDA blocker AP- 5 abolished LTP in both control and stimulated rats but maintained the PPF enhancement in stimulated rats. The observation of enhanced LTP and PPF after tDCS demonstrates that non-invasive electrical stimulation is capable of modifying synaptic plasticity.

Key words: brain stimulation; extracellular recording; hippocampus; long term potentiation; rat; tDCS

\section{Significance Statement}

Researchers have used brain stimulation such as transcranial direct current stimulation on human subjects to alleviate symptoms of neurological disorders and enhance their performance. Here, using rats, we have investigated the potential mechanisms of how in vivo brain stimulation can produce such effect. We recorded directly on viable brain slices from rats after brain stimulation to detect lasting changes in pattern of neuronal activity. Our results showed that 30 min of brain stimulation in rats induced a robust enhancement in synaptic plasticity, a neuronal process critical for learning and memory. Understanding such molecular effects will lead to a better understanding of the mechanisms by which brain stimulation produces its effects on cognition and performance.

\section{Introduction}

Clinical studies have revealed the potential of transcranial direct current stimulation (tDCS) as a therapeutic tool. tDCS can partially reverse motor impairments induced by stroke (Jo et al., 2009) and Parkinson's disease (Boggio et al., 2006) and can compensate for cognitive deficits induced by Alzheimer's

Received June 22, 2015; revised Aug. 7, 2015; accepted Aug. 11, 2015.

Author contributions: K.A.C. and R.J. designed research; J.G.R., S.M.M., and M.K.M. performed research; J.G.R., S.M.M., and M.K.M. analyzed data; J.G.R., K.A.C., and R.J. wrote the paper.

This work was supported by the Air Force Office of Scientific Research award \#13RH14COR, a postdoctoral fellowship award from the National Research Council, and an appointment to the Postgraduate Research Participation Program at the Naval Medical Research Unit-Dayton (NAMRU-D) administered by the 0ak Ridge Institute for Science and Education through an interagency agreement between the U.S. Department of Energy and NAMRU-D. We thank Naomi Bechmann, Raquel Moore, Kevin Schmidt, Saline Hughes, and Justin Stafford for their contribution to this work. disease (Ferrucci et al., 2008; Boggio et al., 2009), depression (Fregni et al., 2006; Loo et al., 2012; Brunoni et al., 2014), schizophrenia (Göder et al., 2013), and posttraumatic stress disorder (Saunders et al., 2015). In addition to these clinical benefits, tDCS use in healthy subjects has been observed to improve declarative and working memory (Marshall et al.,

\footnotetext{
The authors declare no competing financial interests.
}

This article is freely available online through the $J$ Neurosci Author Open Choice option.

Correspondence should be addressed to Dr. Joyce G. Rohan, Naval Medical Research Unit Dayton, Area B, Building 837, 2729 R Street, Wright Patterson Air Force Base, OH 45433. E-mail: Joyce.Rohan.ctr@us.af.mil.

DOI:10.1523/JNEUROSCI.2376-15.2015

Copyright $\odot 2015$ Rohan et al.

This is an Open Access article distributed under the terms of the Creative Commons Attribution License Creative Commons Attribution 4.0 International, which permits unrestricted use, distribution and reproduction in any medium provided that the original work is properly attributed. 
2004; Fregni et al., 2005; Jeon and Han, 2012; Hoy et al., 2013) and other cognitive functions (Fiori et al., 2011; Chrysikou et al., 2013; Martin et al., 2014).

There is an immense volume of work documenting the effects of various forms of electrical stimulation on neuronal activity. In 1956, it was discovered that weak current stimulation in crayfish resulted in subthreshold changes in membrane potential inducing either neuronal hyperpolarization or depolarization, thus translating to either inhibition or excitation, respectively, depending on the polarity of applied current (Terzuolo and Bullock, 1956). It was subsequently demonstrated that a polarizing current applied to the exposed cortex of an anesthetized rat for at least 5 min produced enhancement in evoked response and spontaneous activity that persisted for at least $3 \mathrm{~h}$ after cessation of polarizing current stimulation (Bindman et al., 1962). Follow-up studies in humans later indicated that tDCS lasting at least 5 min applied to the motor cortex induced a significant increase in motor-evoked potential that lasted $90 \mathrm{~min}$ after the end of stimulation (Nitsche and Paulus, 2001). However, excitability enhancement in the motor cortex lasting $>24 \mathrm{~h}$ could be induced by periodical anodal tDCS (Monte-Silva et al., 2013).

Recent work using rats subjected to in vivo anodal tDCS corroborates human studies, revealing increased cortical excitability and improvements in working memory, skill learning, and motor coordination as assessed using a variety of behavioral tests (Dockery et al., 2011; Binder et al., 2014; Romero Lauro et al., 2014). Also consistent with human studies, anodal tDCS has been demonstrated to possess therapeutic potential in rat models of Alzheimer's disease (Yu et al., 2014) and stroke (Jiang et al., 2012). However, the cellular mechanism by which anodal tDCS exerts its effects remains elusive. Based on past studies on the enhancement of learning and memory in both human and animals, there is a general consensus that anodal tDCS could enhance synaptic plasticity, especially long-term potentiation (LTP). In vivo application of tDCS in human subjects produced LTP-like effects in the human cerebral cortex that are dependent on the glutamatergic system and calcium (Nitsche et al., 2008; Stagg and Nitsche, 2011). Similarly, in vivo stimulation in rabbits suggested that tDCS can modify synapses at presynaptic sites that are essential for associative learning (Márquez-Ruiz et al., 2012). In vitro exposures of brain slices to anodal current stimulation enhanced synaptic plasticity in mouse motor cortex (Fritsch et al., 2010) and in CA1 neurons of rat hippocampus (Ranieri et al., 2012). Furthermore, in vitro current stimulation applied directly to rat hippocampal slices has been shown to alter amplitude and frequency of gamma oscillations, mathematically predicted to be induced by changes in synaptic function (Reato et al., 2015).

There is limited data available on the direct effects of in vivo tDCS on cellular LTP. Here, we show that in vivo application of anodal tDCS in rats $(0.25$ or $0.10 \mathrm{~mA}$ for $30 \mathrm{~min})$ induced a significant enhancement in LTP and paired-pulse facilitation (PPF) in the Schaffer collateral-CA1 synapse of the hippocampus. The enhanced effect on LTP in hippocampal slices was dependent on tDCS intensity and persisted for at least $24 \mathrm{~h}$ after completion of tDCS. Additionally, we show that the observed tDCS-enhanced LTP at the Schaffer collateral-CA1 pathway is dependent on NMDA receptors, whereas tDCS-enhanced PPF is independent of NMDA receptors.

\section{Materials and Methods}

Animal handling. All rats were maintained according to National Institutes of Health and Wright Patterson Air Force Base (WPAFB) Institutional Animal Care and Use Committee guidelines. The study protocol
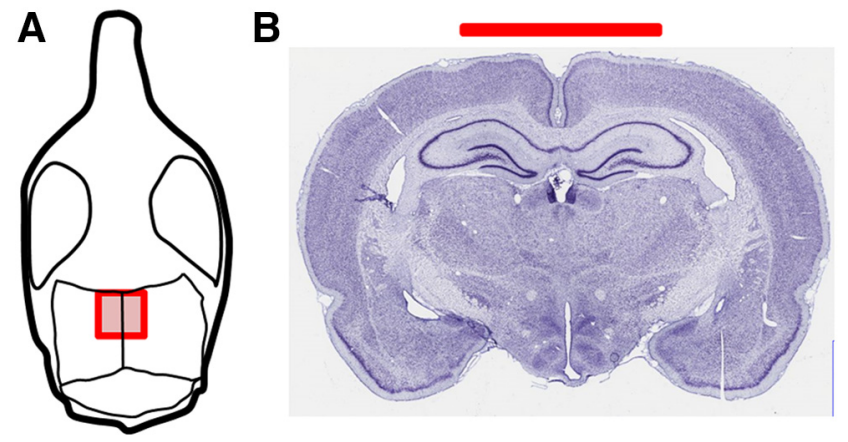

Figure 1. Electrode placement showing approximate size and placement on the rat skull. $\boldsymbol{A}$, Drawing of rat skull to demonstrate the positioning of the electrode in our experimental setup. The electrode was centered on the sagittal suture and ran from 0.0 to $-5.0 \mathrm{~mm}$ caudal to bregma. $\boldsymbol{B}$, The Nissl-stained image (Mikula et al., 2007) shows a coronal tissue section close to the center of the electrode.

was reviewed and approved in compliance with the Animal Welfare Act and with all applicable federal regulations governing the protection of animals in research.

All animals (7-week-old male Sprague Dawley rats) were purchased from Charles River and received a $10 \mathrm{~d}$ acclimation period on arrival to WPAFB facilities before surgical implantation of an electrode. A total of 34 rats were used for this study. Rats were monitored for 1 week to assess recovery before being randomly selected for sham or tDCS treatment.

Surgical implantation of cranial electrode. Animals were anesthetized with isoflurane (Med-Vet International) using 5\% induction, followed by $2-3 \%$ isoflurane to maintain anesthetic depth. A head electrode of $0.25 \mathrm{~cm}^{2}$ (1.25-inch-diameter circular electrode cut to $5 \times 5 \mathrm{~mm}$; ValuTrode; Axelgaard Manufacturing) was applied to the skull with the center of the electrode resting on the midline $2.5 \mathrm{~mm}$ caudal to bregma (Fig. 1). A c-clamp was then placed on the skull with C\&B Metabond Adhesive Luting Cement (Parkell). Acrylic dental cement (Sigma) was then applied. A minimum of $7 \mathrm{~d}$ recovery was permitted before $\mathrm{tDCS}$ treatment.

tDCS treatment. Five minutes before stimulation, animals were removed from the home cage, weighed, and brought to the experimental room. The head electrode was connected to experimental wires, and a reference electrode $\left(8.04 \mathrm{~cm}^{2}\right.$; ValuTrode; Axelgaard Manufacturing) was placed between the shoulders with Signagel electrode gel (Parker Laboratories) as the conducting medium. Once the electrodes were in place, the animal was placed into a novel environment made of Plexiglas, containing two novel objects for exploration. Animals were allowed to move freely throughout stimulation and were monitored via Ethovision software. The use of novel environment placement allowed for enhanced neuronal activity of the target areas during the application of tDCS. tDCS was then applied using a constant-current stimulator (Magstim DCstimulator; Neuroconn) for $30 \mathrm{~min}$ at 250 or $100 \mu \mathrm{A}$. Previous work in our laboratory using histological analysis has shown that these intensities (100 and $250 \mu \mathrm{A}$ ) do not cause tissue damage. The animals in the sham group were connected the same way as the stimulation group but did not receive any current. After stimulation, the animals were returned to their home cage until time they were euthanized for brain slice preparation (30 min or $24 \mathrm{~h}$ after stimulation).

Brain slice preparation. Brain and brain slices were kept viable by keeping in ice-cold artificial CSF (ACSF) that was kept continuously oxygenated $\left(95 \% \mathrm{O}_{2} / 5 \% \mathrm{CO}_{2}\right)$. ACSF consisted of the following (in $\mathrm{mM}$ ): 124 $\mathrm{NaCl}, 3 \mathrm{KCl}, 1.25 \mathrm{KH}_{2} \mathrm{PO}_{4}, 10 \mathrm{D}$-glucose, $1 \mathrm{MgSO}_{4}, 36 \mathrm{NaHCO}_{3}$, and 2 $\mathrm{CaCl}_{2}, \mathrm{pH} \sim 7.4$. Cerebellum and $\sim 1 \mathrm{~cm}$ of frontal cortex were removed, and the remaining brain was sectioned at $350 \mu \mathrm{m}$ using a vibratome (VT1000S from Leica or OTS-4000 from FHC) in the transverse plane, at $20-30^{\circ}$ laterally off the horizontal axis. Brain slices were maintained in warmed oxygenated ACSF and allowed to recover for at least $60 \mathrm{~min}$ before recording. A new batch of ACSF was prepared each morning of experimentation and continuously oxygenated with $95 \% \mathrm{O}_{2}$ and $5 \% \mathrm{CO}_{2}$.

One hippocampal slice was placed onto the precoated MED64 probe, using small weights to anchor the slices down. The probe containing the 
A



B

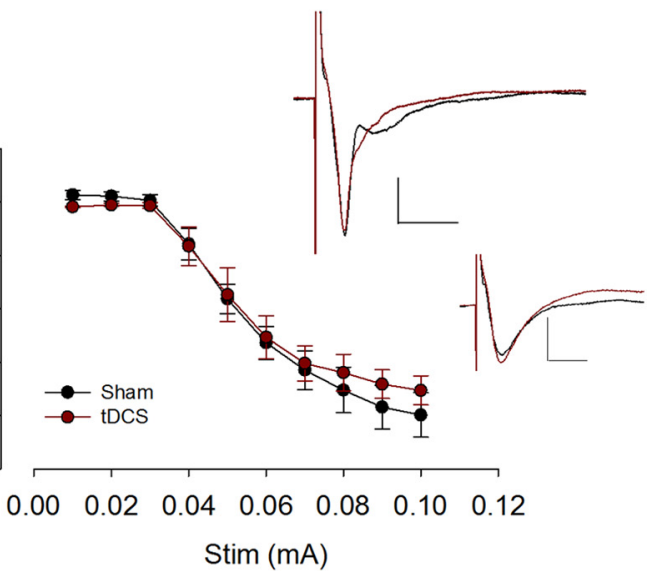

C



Figure 2. A, Typical positioning of our hippocampal slice in the MED64 probe, containing 64 microelectrodes arranged in an $8 \times 8$ array. Dotted rectangular box indicates the hippocampal area that is being recorded, whereas the solid rectangular box indicates the typical position where stimulation occurs. $B$, The input/output relationship was not affected by tDCS treatment $(n=3$ rats, 3 slices). Data are represented as mean \pm SEM. Input consists of a 5 ms biphasic stimulation waveform ranging from $10 \mu \mathrm{A}(-10$ to $10 \mu \mathrm{A})$ to $100 \mu \mathrm{A}(-100$ to $100 \mu \mathrm{A})$ in amplitude. Stimulation input was delivered through the microelectrodes within the Schaffer collateral region indicated by the solid rectangular box to stimulate CA1 neurons. Evoked extracellular potentials from the CA1 region were recorded and plotted against stimulation intensity. Data from all microelectrodes within the dotted rectangular box were averaged together to yield the output value for that particular slice. Sample voltage traces (inset) showing no obvious differences in evoked response between tDCS-treated (red) and control (black) rats. Calibration: $0.4 \mathrm{mV}, 10 \mathrm{~ms}$. Sample voltages shown were recorded from one of the microelectrodes in response to a $50 \mu \mathrm{A}$ (top) or $40 \mu \mathrm{A}$ (bottom) stimulation. C, Frequency of spontaneous activity was not significantly different between control and stimulated rats ( $n=4$ rats, 4 slices, $p=0.5$ ). D, Sample spontaneous spike measurements in a control (top) and stimulated (bottom) rat. Calibration: $0.02 \mathrm{mV}, 5 \mathrm{~s}$.

brain slice was then assembled with the MED64 system, as specified in the MED64 instruction manual. A perfusion cap was used to circulate fresh oxygenated ACSF into the probe and prevent the slices from drying. The ACSF solution and oxygen entering the probe chamber were maintained at $32-34^{\circ} \mathrm{C}$. Flow rates were maintained at $\sim 0.5-1.0 \mathrm{ml} / \mathrm{min}$ while ensuring a liquid-air interphase. Humidified oxygen entered the probe at $\sim 0.3-0.5 \mathrm{~L} / \mathrm{min}$.

Electrophysiology recording. All electrophysiology recordings were blinded experiments, in which the exposure condition of the rat (tDCS or sham) was not identified until the completion of recordings from all rats in the same cohort. A cohort is one group of rats of the same age that has undergone electrode placement surgery on the same day.

All electrophysiology data were obtained using AlphaMed MED64 (Automate), an extracellular recording system containing 64 planar microelectrodes arranged in an $8 \times 8$ array. Data acquisition and stimulation protocols were performed using Mobius software (Automate). A stimulating current of $10-100 \mu \mathrm{A}$ was applied to the Schaffer collateral region of the hippocampus to obtain an input/output relationship curve (Fig. 2). Evoked field potentials in the form of field EPSPs (fEPSPs) and population spikes were obtained in the CA1 region of the hippocampus (Fig. 2) and recorded every 6 s. Using the input/output relationship curve, we determine the size of the stimulating current that resulted in half of the maximal output response. Typically, a stimulating size of $30-50 \mu \mathrm{A}$ induced the half-maximal response and thus was used in our experiments. Baseline recording was obtained for each slice for at least $30 \mathrm{~min}$ before LTP measurements. LTP of CA1 neurons was induced by delivering three trains of theta burst stimulation (TBS), consisting of 10 repeats of four highfrequency stimulation $(100 \mathrm{~Hz}$ ) every $200 \mathrm{~ms}$ to the Schaffer collateral regions. Evoked responses or field potentials (fEPSPs and population spikes) were monitored at $6 \mathrm{~s}$ intervals for at least $30 \mathrm{~min}$ after LTP induction. Percentage potentiation was calculated by computing the percentage difference in population spike amplitude or fEPSP slope at either 30 or $60 \mathrm{~min}$ after LTP induction by TBS from baseline. Averages of five data points were calculated to obtain baseline and LTP values. PPF was obtained by delivering two consecutive stimuli at 50 $\mu \mathrm{A}$ that are $40 \mathrm{~ms}$ apart. To ensure that facilitation was not present at $24 \mathrm{~h}$, additional recordings were made with paired stimuli at 30 and 40 $\mu \mathrm{A}$. Responses mediated by the AMPA and kainate receptors were blocked using $30 \mu \mathrm{M}$ 6,7-dinitroquinoxaline-2,3(1H,4H)-dione (DNQX; Sigma). NMDA receptors were blocked using $50 \mu \mathrm{M} \mathrm{D}(-)$ 2-amino-5-phosphonopentanoic acid (AP-5; Sigma).

Data analysis. fEPSPs were calculated by fitting a line to the initial rise of the evoked response and calculating the slope in the CA1 region. Amplitudes of population spikes were also calculated. Slope and amplitude calculations were performed using Mobius software (Automate). Quantitation of LTP was obtained by averaging five data points at the indicated times (just before LTP induction by TBS and at 30 or 60 min after TBS). Percentage LTP or percentage potentiation refers to the slope or amplitude of fEPSP at either 30 or $60 \mathrm{~min}$ after TBS minus the slope or amplitude of baseline fEPSP before TBS divided by the slope or amplitude of baseline fEPSP values. Normalized fEPSP data refers to the slope or amplitude of fEPSP divided by the average slope or amplitude of all fEPSP points before TBS. Quantita- 

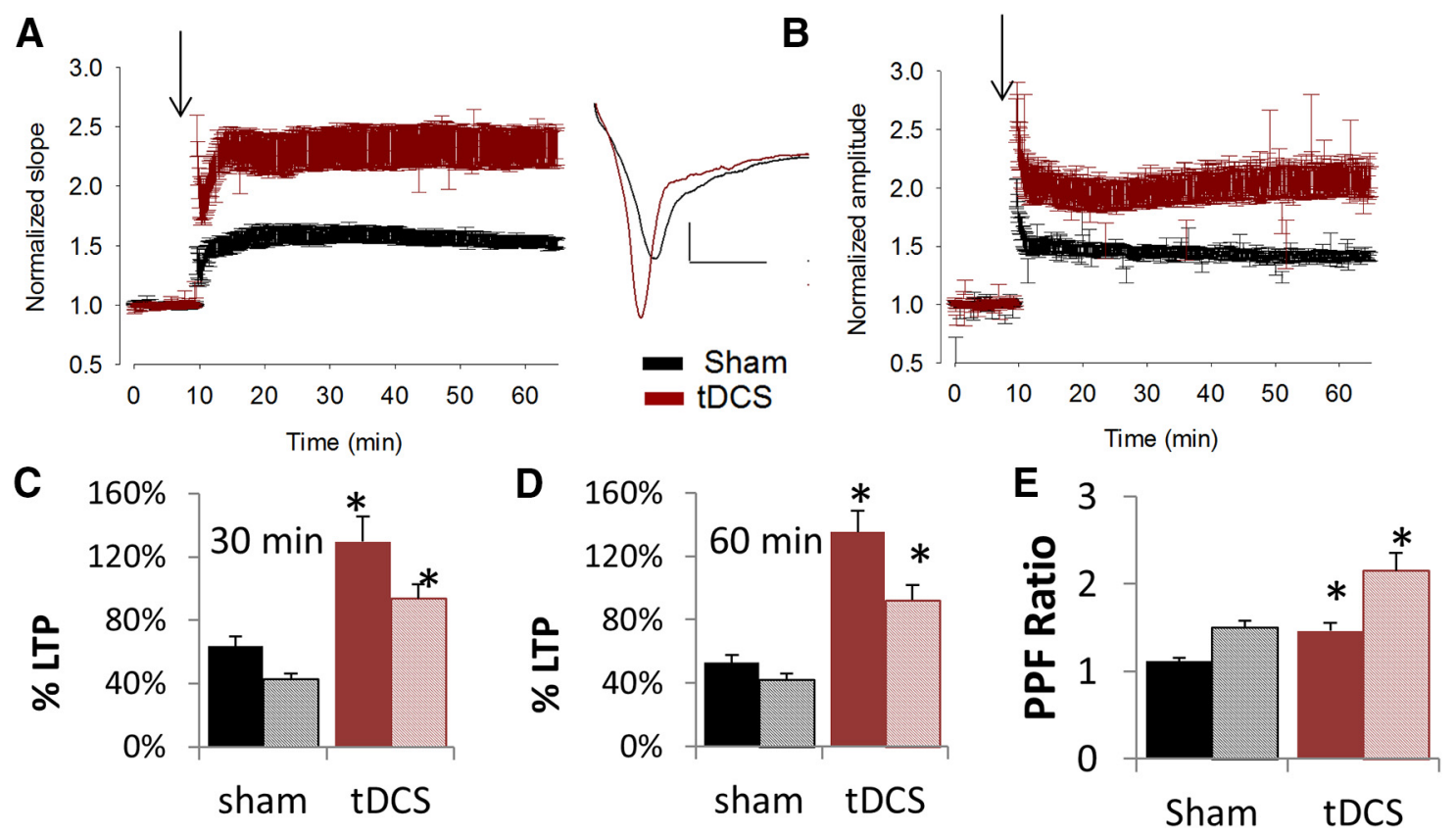

Figure 3. Effects of tDCS on synaptic plasticity. Rats were subjected to tDCS for $30 \mathrm{~min}$ at $250 \mu \mathrm{A}$, followed by 30 min additional recovery time. $\boldsymbol{A}-\boldsymbol{D}$, Effects of tDCS on LTP. $\boldsymbol{A}$, Graph of average, normalized slopes of evoked responses from CA1 region of hippocampus from control (Sham, black trace, $n=6$ rats, 8 slices) or stimulated (tDCS, red trace, $n=6$ rats, 7 slices) rats. Data are presented as means \pm SEMs. Arrow denotes induction of LTP by TBS. Sample trace of evoked response before (black) and $\sim 30$ min after (red) LTP induction by TBS is shown to the right (inset). Calibration: $0.5 \mathrm{mV}, 5 \mathrm{~ms}$. $\boldsymbol{B}$, Graph of average, normalized amplitudes of evoked responses from CA1 region of hippocampus from control (Sham, black trace, $n=6$ rats, 8 slices) or stimulated (tDCS, red trace, $n=6$ rats, 7 slices) rats. Arrow denotes induction of LTP by TBS. Data are presented as means \pm SEMs. C, D, Bar graph representing the average percentage LTP calculated using slopes (solid fill) and amplitudes (pattern fill) of evoked responses at 60 min after LTP induction (C) or 30 min after LTP induction (D). Significant enhancements were observed in hippocampal slices from tDCS-treated rats (red) compared with sham-treated rats (black) (slope data, $p=0.002$ and 0.01 for 60 and 30 min, respectively; amplitude data, $p=0.0005$ and 0.0002 for 60 and 30 min, respectively; $d f=13$ ). $E$, Effects of tDCS on PPF. The PPF ratio was calculated as slope (solid fill) or amplitude (pattern fill) of response resulting from the second stimulus divided by the respective slope or amplitude of response resulting from the first stimulus. There was a significant increase in PPF ratio in the CA1 region of the hippocampus from rats treated with $\operatorname{tDCS}(n=5$ rats, 6 slices) compared with that from control ( $n=5$ rats, 7 slices; $p=0.003$ and 0.005 for slope and amplitude data, respectively; $\mathrm{df}=65$ ). Data are presented as means \pm SEMs. ${ }^{*} p<0.05$.

tion of PPF was obtained by dividing the slope or amplitude of the fEPSP response resulting from the second stimulus divided by the slope or amplitude of the fEPSP response resulting from the first stimulus to obtain the PPF ratio. Data from multiple MED64 microelectrodes within the CA1 region of a hippocampal slice were averaged together to obtain the response from that particular slice. Typically, one to two hippocampal slices per rat were used, and $n$ values are indicated as the number of rats followed by the number of slices used. For our PPF data analysis, multiple stimulations at distinct locations in one slice were performed, and various microelectrodes within the CAl region were recorded and counted as the sample size in the statistical analysis of this data.

Data are represented as means with the SEM and were compared statistically using an unpaired, two-tailed $t$ test. A calculated $p$ value of $<0.05$ is considered significantly different. All quantitation and statistical analysis as well as graphs were generated using Microsoft Excel and SigmaPlot version 12.5 (Systat Software).

\section{Results}

In vivo anodal tDCS in rats enhanced LTP in acutely prepared hippocampal slices

To determine the optimum stimulation intensity for LTP experiments, we applied multiple stimulating currents to the Schaffer collateral region of rat hippocampal slices ranging from 10 to $100 \mu \mathrm{A}$ in intensity (Fig. 2A). We found that a current of $50 \mu \mathrm{A}$ consistently induced half-maximal response, and thus a $50 \mu \mathrm{A}$ current was used as stimulus for our electrophysiological experiments. There was no obvious effect on the size and shapes of the evoked response in the hippocampus of control or stimulated rats (Fig. 2B). Furthermore, tDCS did not induce significant changes in the frequency of spontaneous spiking activity in the CA1 region of the hippocampus resulting from tDCS (Fig. 2C). There may be subtle activation of fast spiking interneurons surrounding the CA1 region (Fig. $2 C, D)$, but this activation was only observed in two of four slices and was not statistically significant. Follow-up study is worth pursuing to determine tDCS effects on the fast spiking interneurons of the hippocampal CA3 region, in which highfrequency spiking has been shown to be more prominent and can be induced reliably.

LTP was induced using three trains of TBS. We found that there was a significant increase in the degree of LTP in rats that were subjected to tDCS compared with control rats (Fig. 3). By calculating the initial slope of the field potentials at $30 \mathrm{~min}$ after LTP induction using TBS, there was a $63.7 \pm 6 \%$ potentiation in control rats (sham) but a $129.6 \pm 16 \%$ potentiation in stimulated rats (tDCS; Fig. $3 A, C$ ). At $60 \mathrm{~min}$, the difference is further enhanced, resulting in $52.9 \pm 5 \%$ potentiation in control rats and $135.2 \pm 14 \%$ in stimulated rats (Fig. $3 A, D)$. Statistical analysis using unpaired, two-tailed $t$ test yielded $p$ values of 0.01 and 0.002 for the 30 and $60 \mathrm{~min}$ slope data, respectively. Amplitudes of field potentials were also calculated, yielding a $42.8 \pm 3$ and $93.5 \pm 9 \%$ potentiation in control and tDCS-treated rats, respectively, at the $30 \mathrm{~min}$ time point, and $42.3 \pm 4$ and $92.3 \pm$ $9 \%$ potentiation in control and tDCS-treated rats, respectively, at the 60 min time point (Fig. $3 B, E, F$ ). $p$ values were $<0.001$ for both the 30 and $60 \mathrm{~min}$ amplitude data. The differences observed at $30 \mathrm{~min}$ were always observed at $60 \mathrm{~min}$ and were of a greater magnitude (Fig. $3 D)$. Therefore, in subsequent experiments, the percentage LTP po- 
tentiation of evoked responses were calculated only at the $30 \mathrm{~min}$ time point after LTP induction.

\section{Anodal tDCS in rats enhanced PPF in} acutely prepared hippocampal slices PPF measurements were obtained by delivering two $50 \mu \mathrm{A}$ stimuli that are $40 \mathrm{~ms}$ apart to the Schaffer collateral region of the hippocampus, and evoked responses from CA1 region were recorded. We found that there was significantly greater PPF in stimulated rats compared with control rats (Fig. $3 E$ ). Rats subjected to 30 min of tDCS $(250 \mu \mathrm{A})$ followed by $30 \mathrm{~min}$ recovery time displayed a PPF ratio of $1.5 \pm 0.04$ compared with $1.1 \pm 0.09$ of control rats when slope measurements were used ( $p=0.003)$. Similarly, PPF ratio values based on amplitude calculations were $1.5 \pm 0.1$ and $2.2 \pm 0.07$ for control and tDCS-treated rats, respectively $(p=$ 0.005).

\section{Dependence of synaptic plasticity on tDCS intensity}

The enhancing effect on LTP and PPF was still observed, albeit to a smaller extent, when tDCS intensity was decreased from 250 to $100 \mu \mathrm{A}$ (Fig. 4A,D). Hippocampal slices obtained from rats treated with 30 min of $100 \mu \mathrm{A}$ tDCS followed by $30 \mathrm{~min}$ recovery time resulted in a percentage LTP of $118.5 \pm 16 \%$ compared with $83 \pm$ $7 \%$ from control rats (sham) as measured by calculating the slopes of field potentials $(p=0.01$; Fig. $4 B)$. Amplitude measurements were $54 \pm 7 \%$ LTP for control rats and $88 \pm 17 \%$ for stimulated rats $(p=$ $0.04)$. Furthermore, slopes of evoked responses in hippocampal slices from tDCS-treated rats still displayed a greater PPF ratio $(1.7 \pm 0.1)$ compared with shamtreated rats $(1.3 \pm 0.05$; Fig. $4 D ; p=0.002)$. Amplitude values for the PPF ratio were $2.4 \pm 0.06$ and $1.6 \pm 0.2$ for tDCS- and sham-treated rats, respectively (Fig. $4 D ; p=0.006$ ).

\section{Lasting effects of tDCS on synaptic plasticity}

To determine whether the effects to tDCS were persistent, animals received in vivo tDCS stimulation for $30 \mathrm{~min}$ and then were returned to their home cage for $24 \mathrm{~h}$. We observed that the effect of tDCS on LTP was still maintained $24 \mathrm{~h}$ after tDCS (Fig. 5). Using field potential slope values, the sham group experienced an average LTP of $76 \pm 9 \%$, whereas the tDCS group experienced an average LTP of $154 \pm 35 \%(p=0.03$, $n=7$ rats, 8 slices). Similarly, using amplitude values, the sham group experienced an average LTP of $47 \pm 8 \%$, whereas the tDCS group experienced an average LTP of $155 \pm 48 \%$ $(p=0.02)$. Unlike the data obtained from rats $30 \mathrm{~min}$ after tDCS, data obtained from rats $24 \mathrm{~h}$ after tDCS did not reveal significant changes in PPF. We stimulated hippocampal slices with two consecutive stimuli that are $40 \mathrm{~ms}$ apart at three
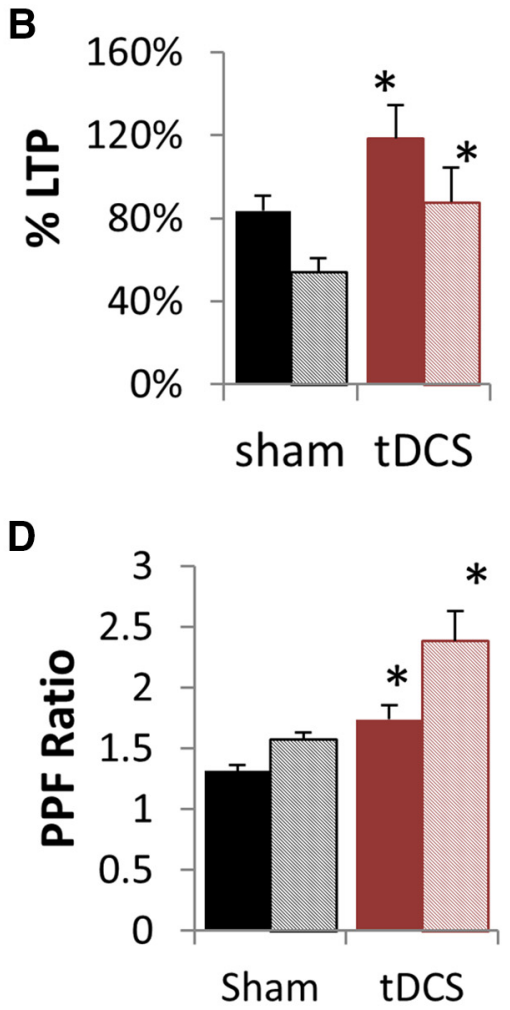

Figure 4. Effects of decreased tDCS intensity on synaptic plasticity. $\boldsymbol{A}-\boldsymbol{C}$, Schaffer collateral-CA1 LTP was significantly enArrow denotes LTP induction by TBS. B, Bar graph showing significant increases in the average percentage LTP resulting min of $100 \mu A \operatorname{tDCS}(p=0.01$ and 0.04 for slope and amplitude data, respectively; $\mathrm{df}=10$ ). Percentage LTP was calculated using (solid fill) or amplitudes of population spikes (pattern fill) recorded in the (A1 region ( $n=4$ rats, 5 slices). sham data. $\boldsymbol{D}$, Rats subjected to $100 \mu \mathrm{A}$ tDCS displayed significant enhancement of PPF as measured by slope (solid fill; $p=0.002$, $\mathrm{df}=42$ ) or amplitude (pattern fill; $p=0.006, \mathrm{df}=42$ ). ${ }^{*} p<0.05$.

different intensities $(30,40$, and $50 \mu \mathrm{A})$ and did not detect any significant effects on the PPF ratio $(p>0.1)$.

\section{Dependence of tDCS-mediated plasticity effects on NMDA receptors}

The observed field potentials from CA1 neurons were mediated predominantly by ionotropic glutamate receptors (iGluRs) because the evoked response was abolished quickly by the perfusion of $30 \mu \mathrm{M}$ DNQX and $50 \mu \mathrm{M}$ AP-5 in hippocampal slices from both control and tDCS rats (Fig. 6). Application of $50 \mu \mathrm{M}$ AP- 5 only minimally reduced the evoked response but prevented LTP induction in both sham and tDCS-treated rats (Fig. 6A-C). However, the enhanced effect on PPF was still observed in the presence of AP-5 (Fig. 6D). This suggests that the tDCS-induced increase in PPF is not NMDA dependent, because blockade of NMDA receptor still induced PPF ratios of $1.4 \pm 0.1$ in tDCS-treated rats compared with a PPF ratio of $1.1 \pm 0.08$ in control rats when slope values were used $(p=0.02)$ and PPF ratios of $2.7 \pm 0.5$ and $1.6 \pm 0.2$ in stimulated and control rats, respectively, when amplitude values were used ( $p=0.03$ ). Our data are consistent with the previously established principles claiming that calcium accumulation in the presynaptic terminal is critical in establishing 

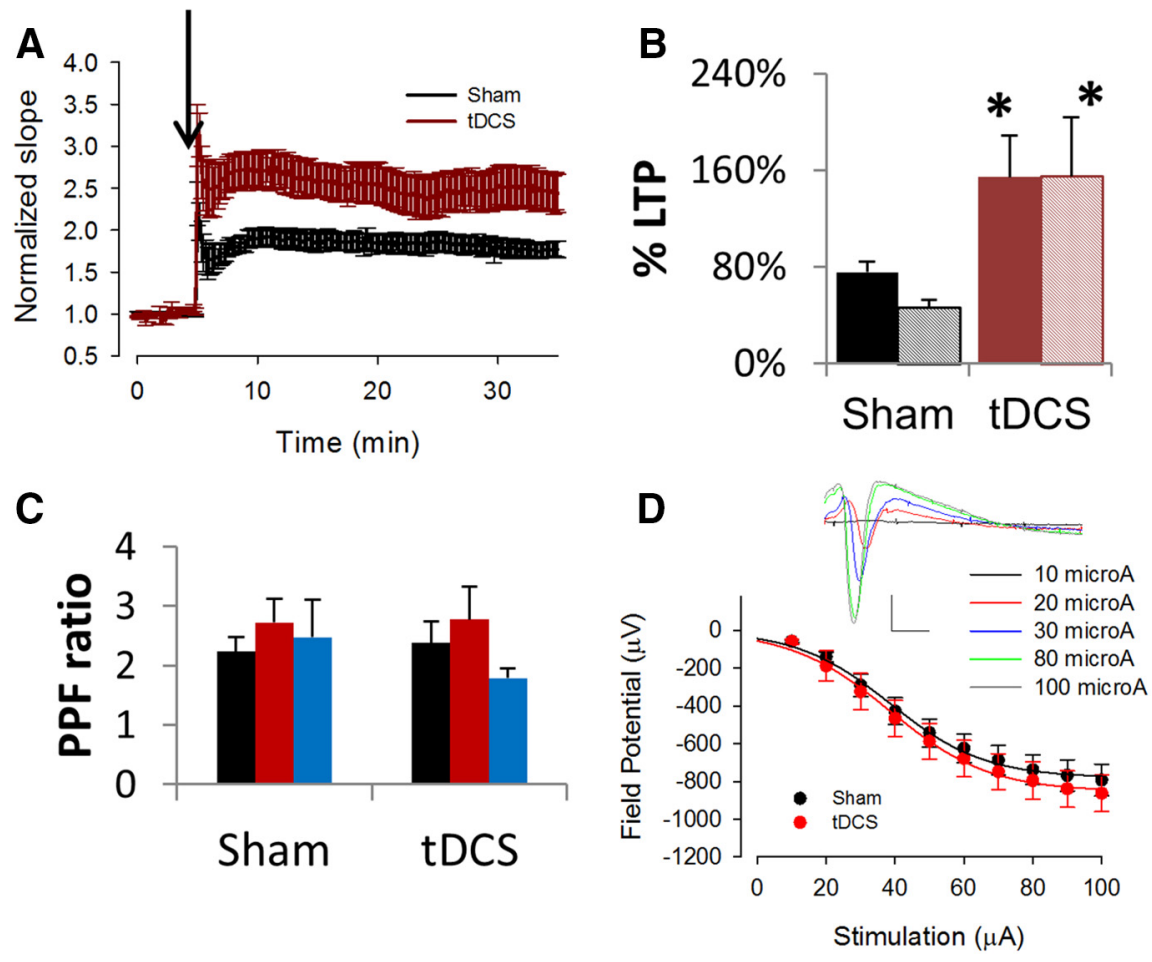

Figure 5. Effects of tDCS on synaptic plasticity assessed in $24 \mathrm{~h} . \boldsymbol{A}, \boldsymbol{B}, \mathrm{LTP}$ was enhanced in rats $24 \mathrm{~h}$ after treatment with $\mathrm{DDCS}$ ( $250 \mu \mathrm{A}, 30 \mathrm{~min})$. $A$, Average, normalized slope showing enhanced LTP in tDCS-treated rats (red) compared with sham-treated rats (black). $\boldsymbol{B}$, Bar graph of average percentage LTP showing significant enhancement of LTP in stimulated rats (red; $n=7$ rats, 10 slices) compared with control (black; $n=7$ rats, 8 slices, unpaired 2-tailed $t$ test) as measured using either slope data (solid fill; $p=$ $0.03, \mathrm{df}=16$ ) or amplitude data (pattern fill; $p=0.02, \mathrm{df}=16) .{ }^{*} p<0.05$. C, PPF was not altered significantly in rats $24 \mathrm{~h}$ after treatment with $\operatorname{tDCS}(p=0.3-0.9)$. Stimuli were set at 30 (black), 40 (red), and 50 (blue) $\mu$ A. Amplitude measurements were obtained to generate graphs. Slope measurements also produced no significant changes in the PPF ratio (data not shown). $\boldsymbol{D}$, General neurotransmission property was unaltered in rats $24 \mathrm{~h}$ after treatment with $\mathrm{TDCS}$. Average input/output relationship was similar in sham (black) and tDCS (red) rats. Sample traces of field potentials evoked by stimuli of varying intensity, as indicated. Calibration: $5 \mathrm{~ms}, 0.5 \mathrm{mV}$.

PPF (Zucker, 1989; Zucker and Regehr, 2002; Madroñal et al., 2009). We believe this is the first account of in vivo tDCS enhancing plasticity of neurons at both the presynaptic and postsynaptic sites of rat hippocampus.

\section{Discussion}

We have demonstrated that in vivo tDCS in rats can enhance LTP and PPF, two distinct types of synaptic plasticity in the rat hippocampus. Reduction of tDCS intensity from 200 to $100 \mu \mathrm{A}$ decreased the LTP enhancement to $\sim 1$-4-fold, supporting the possibility of dose-dependent effects. This is consistent with previous findings in which modulation of cortical excitability was dependent on current stimulation intensity (Nitsche and Paulus, 2000; Bastani and Jaberzadeh, 2013; Murray et al., 2015). Of interest, the effect on PPF appears to be all-or-none, enhancing PPF by 30$50 \%$ at both the high and low tDCS intensities. Although the increase in PPF can no longer be detected at $24 \mathrm{~h}$ after completion of tDCS, the LTP enhancement still persists, suggesting the possibility that tDCS-mediated enhancements of LTP and PPF occur through distinct mechanisms. Our data further suggest that the tDCSinduced increase in LTP is NMDA dependent, which is consistent with previously established principles that postsynaptic NMDA receptors play a critical role in LTP at the CA1 region of the hippocampus, as well as with other studies demonstrating that tDCS-induced effects can be blocked by NMDA blockers (Liebetanz et al., 2002; Nitsche et al., 2003). Although we did not observe significant changes in spike frequency attributable to tDCS, there may be some activation of highfrequency responses most likely attributable to the fast-spiking hippocampal interneurons. Investigation of tDCS effects on interneuron activity will be pursued. Components of evoked responses in the CA1 region were mediated primarily by iGluRs, because perfusion of the kainate and AMPA blocker DNQX, combined with the NMDA blocker AP-5, blocked all excitatory-evoked responses from both control and stimulated rats. Our data rule out the mechanistic possibility of tDCS producing effects that recruit or enhance other nonglutamatergic synapses in the measured CA1 region of the hippocampus.

A rigorously studied form of synaptic plasticity is LTP, discovered first in the perforant path of an anesthetized rabbit (Bliss and Lomo, 1973). Additional work in brain slices revealed that the CA1 pyramidal cells of the rat hippocampus consistently undergo LTP during highfrequency stimulation (Dunwiddie and Lynch, 1978). Since then, LTP has been studied extensively not only in the hippocampus but also in other brain regions, and it has been widely accepted as the molecular basis for learning and memory (Izquierdo, 1994; Gruart et al., 2006; Whitlock et al., 2006; Neves et al., 2008). Although the complete molecular mechanisms of LTP remain under investigation, many of the key players have been identified (Baudry and Lynch, 2001). Data suggest that high-frequency stimulation induced recruitments of postsynaptic iGluRs onto the postsynaptic cell, as well as gene expression changes (Baudry and Lynch, 2001). Although there are different types of LTP, a robust and well studied form is the NMDA-dependent LTP that persists in the Schaffer collateral-CA1 region of the hippocampus. NMDAdependent LTP has been shown to be essential for learning and memory administration of NMDA receptor blocker AP-5 prevented LTP induction and impaired learning (Izquierdo, 1994; Gruart and Delgado-García, 2007; Caroni et al., 2012).

The tDCS-induced enhancement of LTP observed in this study is consistent with previous findings of improved cognitive functions and plasticity in diseased and healthy subjects resulting from in vivo non-invasive stimulations (Nitsche et al., 2008; Stagg and Nitsche, 2011; Bastani and Jaberzadeh, 2013; Heise et al., 2014). Furthermore, our data are also in agreement with previous work that in vitro current stimulation directly on brain slices resulted in immediate augmentation of NMDA-dependent LTP in the Schaffer collateral-CA1 pathway of rat hippocampus (Ranieri et al., 2012) and the NMDA and BDNF-dependent LTP in the mouse motor cortex (Fritsch et al., 2010). We measured LTP only on the Schaffer collateral-CA1 pathway of the hippocampus that is mainly NMDA dependent. Therefore, we questioned whether the observed effect on LTP was attributable to increased recruitment of other glutamate receptors to the postsynaptic site to generate other types of LTP that is not dependent on NMDA receptors. However, this idea was ruled out by the fact that per- 
A

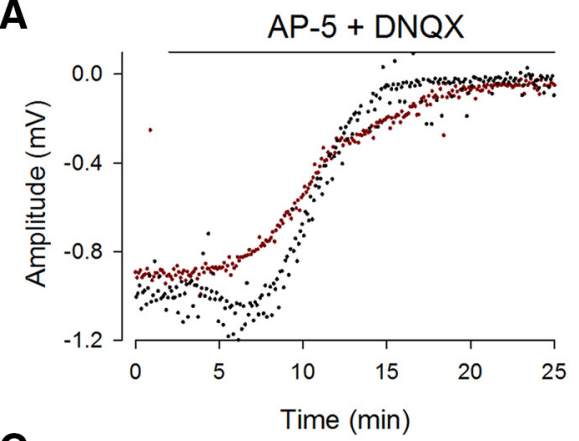

B



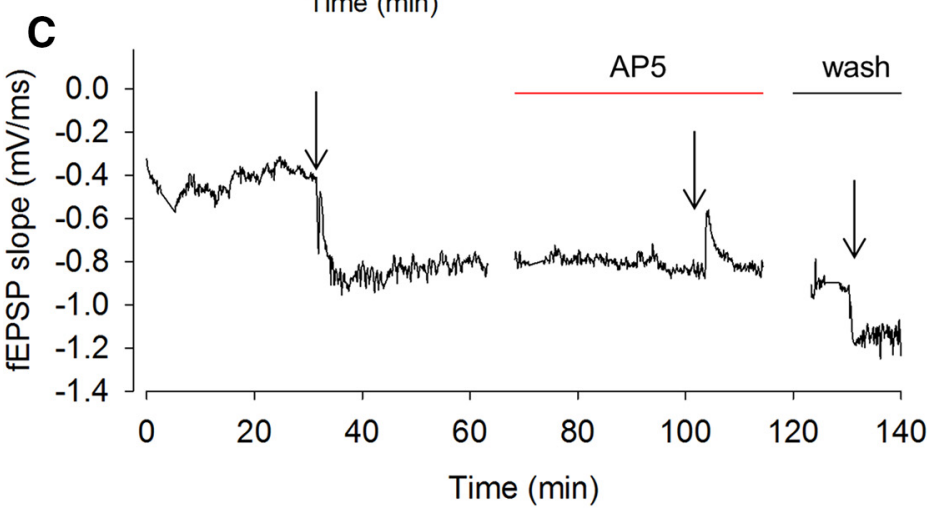

D

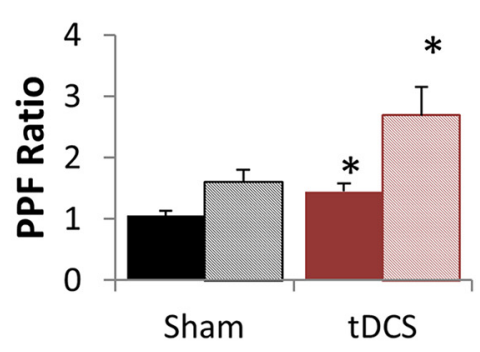

Figure 6. Effects of glutamate receptor blockers on tDCS effects. Rats were subjected to $100 \mu \mathrm{A}$ for $30 \mathrm{~min}$, followed by 30 min recovery time. $A$, Measured evoked response mostly mediated by iGluR as blockade of kainate, AMPA, and NMDA receptors by a mixture of $30 \mu \mathrm{M} \mathrm{DNQX} \mathrm{and} 50 \mu \mathrm{M}$ AP-5 diminished evoked responses from CA1 regions of the hippocampus from both stimulated (red) and control (black) rats. Bar denotes perfusion of DNQX and AP-5. Blockade of NMDA receptor only by AP- 5 did not induce measureable changes in field potentials as shown by the sample recording (right inset), showing only a slight change in response size attributable to AP-5 perfusion (red) but a dramatic blockade of response attributable to both AP-5 and DNQX (blue) compared with ACSF only (black) (inset). Calibration: $10 \mathrm{~ms}, 0.5 \mathrm{mV}$. B, Blockade of NMDA receptors by AP-5 diminished LTP in both control (black) and tDCS-treated (red) rats when calculated using fEPSP slope (solid fill) or amplitude (patterned fill). C, Sample recording from IDCS-treated rat hippocampus showing initial LTP induction (first arrow) in the presence of normal ACSF, blockade of LTP induction in the presence of ACSF and AP-5 (second arrow), and normal LTP induction after wash of AP-5 (third arrow). Arrows denote LTP induction by TBS. Red bar indicates perfusion of AP-5. Black bar indicates return to perfusion of normal ACSF. $D$, Effect on PPF enhancement attributable to tDCS was not altered by AP-5 perfusion. In the presence of AP-5, there was still a significant enhancement of PPF ( $n=2$ rats, 4 slices) in rats subjected to tDCS (red) compared with sham (black) when both slopes (solid fill; $p=0.02, \mathrm{df}=14$ ) or amplitudes (pattern fill; $p=0.03, \mathrm{df}=14$ ) values were used for calculation. ${ }^{*} p<0.05$.

fusion of AP-5 blocks LTP in both control and tDCS-treated rats. Although this does not eliminate the possibility that tDCS can also affect other non-NMDA forms of LTP, it strengthens the hypothesis that the NMDA receptor is an essential target whereby tDCS exerts its effect, at least in the Schaffer collateral-CA1 pathway.

PPF is another form of synaptic plasticity, but, in contrast to LTP, it is short-lived and mediated presynaptically, resulting from accumulation of calcium ions attributable to two stimulating pulses delivered within a short interpulse duration (Zucker 1989; Zucker and Regehr, 2002). PPF is observed when two consecutive stimuli are delivered, within tens of milliseconds of each other, resulting in a potentiated postsynaptic response elicited by the second stimulus. The prevailing mechanistic explanation of PPF is the transient buildup of calcium ions during two consecutive stimuli (Katz and Miledi, 1968; Thomson, 2000). The second stimulus produces an unusually larger calcium pool, which will subsequently trigger greater release of neurotransmitter molecules. This is unlike LTP in which the likely mechanism involves mainly postsynaptic events, such as the recruitment of more iGluRs.

We saw an enhancement in PPF of CA1 neurons from rats subjected to $30 \mathrm{~min}$ of tDCS that persists in the presence of the NMDA receptor blocker AP-5. This is consistent with the idea that facilitation is attributable to the accumulation of calcium in the presynaptic cell (Katz and Miledi, 1968; Thomson, 2000) and thereby NMDA receptor independent. However, our data of enhanced PPF contradicts previous work in rabbits, in which anodal stimulation induced a decrease in the PPF ratio (Márquez-Ruiz et al., 2012). The discrepancy may be accounted by the difference in the probability of neurotransmitter release resulting from the first pulse. We recorded evoked potentials from CA1 neurons in rat ex vivo hippocampal slices, which are known to have a low probability of initial release (Abbott and Regehr, 2004), whereas Márquez-Ruiz et al. (2012) recorded from the rabbit somatosensory cortex in vivo, which has a high probably of initial release (Silver et al., 2003).

In contrast to effects on LTP, the tDCS-induced enhancement on PPF can no longer be detected $24 \mathrm{~h}$ after cessation of stimulation. Although there is convincing correlation between anodal tDCS with increased cortical excitability, there is very limited data on whether stimulation can modify presynaptic machinery. Our data on PPF provide a glimpse on tDCS effect on the presynaptic cell, supporting the hypothesis that neurotransmitter levels at synapses could also be modulated by tDCS.

The unique aspect of our experimental approach is the combination of in vivo treatments with tDCS, followed by extracellular recordings of neurons in freshly prepared hippocampal slices. Such an ex vivo approach may explain why we did not observe lasting changes in our evoked potentials, inconsistent with a previous study (Bindman et al., 1964). In addition, the orientation specificity of tDCS effects (Kabakov et al., 2012) may mask effects on evoked potentials from a population of neurons arranged in various orientations in a hippocampal slice. Changes in synaptic plasticity were observed in these hippocampal slices hours after 
brain extraction at $30 \mathrm{~min}$ and $24 \mathrm{~h}$ after completion of tDCS. For our experiments, brains from both control and stimulated rats were harvested, and hippocampal slices were prepared and placed in oxygenated ACSF for 1-6 h before any recording. Therefore, transient electrical field effects of local environment would have dissipated and could not account for the observed enhancements in synaptic plasticity. We observed no significant differences in the effects on LTP and PPF on slices recorded in the beginning of the day versus toward the end of the experiment (spanning 4-6 h). Averaged normalized responses from six CA1 regions within a hippocampal slice from a stimulated rat measured toward the beginning of an experiment showed similar levels of potentiation as those from another slice from the same rat measured toward the end of the day (data not shown).

We propose the possibility that the immediate effects of tDCS on local electrical environment induced additional downstream signaling events that persist for hours after brain extraction. Cellular changes attributable to tDCS have been documented previously. A previous study by Raneiri et al. (2012) indicated that in vitro current stimulation of brain slices results in immediate increases in the c-fos and zif268, immediate early genes implicated in the maintenance of long-term neuronal changes and memory formation (Pérez-Cadahía et al., 2011). However, we cannot rule out the possibility of other faster signaling events, such as phosphorylation, recruitment, or shuffling of various synaptic proteins, in mediating tDCS effects. Experiments in which inhibitors or activators are used to block particular signaling cascades will be useful in determining the mechanistic pathway of tDCSinduced enhancements in synaptic plasticity.

We have demonstrated that in vivo tDCS induces a longlasting enhancement of NMDA-dependent synaptic plasticity in the hippocampus of rats. These plastic changes may be the mechanism by which tDCS application facilitates performance in healthy human subjects or alleviates symptoms in patients suffering from neurological disorders. We believe that our approach of in vivo $\mathrm{tDCS}$ and direct recordings of neuronal signaling in acutely prepared hippocampal slices will continue to yield useful information pertaining to mechanisms of tDCS effects.

\section{References}

Abbott LF, Regehr WG (2004) Synaptic computation. Nature 431:796-803. CrossRef Medline

Bastani A, Jaberzadeh S (2013) Differential modulation of corticospinal excitability by different current densities of anodal transcranial direct current stimulation. PLoS One 8:e72254. CrossRef Medline

Baudry M, Lynch G (2001) Remembrance of arguments past: how well is the glutamate receptor hypothesis of LTP holding up after 20 years? Neurobiol Learn Mem 76:284-297. CrossRef Medline

Binder S, Berg K, Gasca F, Lafon B, Parra LC, Born J, Marshall L (2014) Transcranial slow oscillation stimulation during sleep enhances memory consolidation in rats. Brain Stimul 7:508-515. CrossRef Medline

Bindman LJ, Lippold OC, Redfearn JW (1962) Long-lasting changes in the level of the electrical activity of the cerebral cortex produced by polarizing currents. Nature 196:584-585. CrossRef Medline

Bindman LJ, Lippold OC, Redfearn JW (1964) The action of brief polarizing currents on the cerebral cortex of the rat (1) during current flow and (2) in the production of long-lasting after-effects. J Physiol 172:369-382. CrossRef Medline

Bliss TV, Lomo T (1973) Long-lasting potentiation of synaptic transmission in the dentate area of the anaesthetized rabbit following stimulation of the perforant path. J Physiol 232:331-356. CrossRef Medline

Boggio PS, Ferrucci R, Rigonatti SP, Covre P, Nitsche M, Pascual-Leone A, Fregni F (2006) Effects of transcranial direct current stimulation on working memory in patients with Parkinson's disease. J Neurol Sci 249: 31-38. CrossRef Medline

Boggio PS, Khoury LP, Martins DC, Martins OE, de Macedo EC, Fregni F (2009) Temporal cortex direct current stimulation enhances perfor- mance on a visual recognition memory task in Alzheimer disease. J Neurol Neurosurg Psychiatry 80:444-447. CrossRef Medline

Brunoni AR, Boggio PS, De Raedt R, Benseñor IM, Lotufo PA, Namur V, Valiengo LC, Vanderhasselt MA (2014) Cognitive control therapy and transcranial direct current stimulation for depression: a randomized, double-blinded, controlled trial. J Affect Disord 162:43-49. CrossRef Medline

Caroni P, Donato F, Muller D (2012) Structural plasticity upon learning: regulation and functions. Nat Rev Neurosci 13:478-490. CrossRef Medline

Chrysikou EG, Hamilton RH, Coslett HB, Datta A, Bikson M, ThompsonSchill SL (2013) Noninvasive transcranial direct current stimulation over the left prefrontal cortex facilitates cognitive flexibility in tool use. Cogn Neurosci 4:81-89. CrossRef Medline

Dockery CA, Liebetanz D, Birbaumer N, Malinowska M, Wesierska MJ (2011) Cumulative benefits of frontal transcranial direct current stimulation on visuospatial working memory training and skill learning in rats. Neurobiol Learn Mem 96:452-460. CrossRef Medline

Dunwiddie T, Lynch G (1978) Long-term potentiation and depression of synaptic responses in the rat hippocampus: localization and frequency dependency. J Physiol 276:353-367. CrossRef Medline

Ferrucci R, Mameli F, Guidi I, Mrakic-Sposta S, Vergari M, Marceglia S, Cogiamanian F, Barbieri S, Scarpini E, Priori A (2008) Transcranial direct current stimulation improves recognition memory in Alzheimer disease. Neurology 71:493-498. CrossRef Medline

Fiori V, Coccia M, Marinelli CV, Vecchi V, Bonifazi S, Ceravolo MG, Provinciali L, Tomaiuolo F, Marangolo P (2011) Transcranial direct current stimulation improves word retrieval in healthy and nonfluent aphasic subjects. J Cogn Neurosci 23:2309-2323. CrossRef Medline

Fregni F, Boggio PS, Nitsche M, Bermpohl F, Antal A, Feredoes E, Marcolin MA, Rigonatti SP, Silva MT, Paulus W, Pascual-Leone A (2005) Anodal transcranial direct current stimulation of prefrontal cortex enhances working memory. Exp Brain Res 166:23-30. CrossRef Medline

Fregni F, Boggio PS, Nitsche MA, Marcolin MA, Rigonatti SP, Pascual-Leone A (2006) Treatment of major depression with transcranial direct current stimulation. Bipolar Disord 8:203-204. CrossRef Medline

Fritsch B, Reis J, Martinowich K, Schambra HM, Ji Y, Cohen LG, Lu B (2010) Direct current stimulation promotes BDNF-dependent synaptic plasticity: potential implications for motor learning. Neuron 66:198-204. CrossRef Medline

Göder R, Baier PC, Beith B, Baecker C, Seeck-Hirschner M, Junghanns K, Marshall L (2013) Effects of transcranial direct current stimulation during sleep on memory performance in patients with schizophrenia. Schizophr Res 144:153-154. CrossRef Medline

Gruart A,Delgado-GarcíaJM (2007) Activity-dependent changes of thehippocampal CA3-CA1 synapse during the acquisition of associative learning in conscious mice. Genes Brain Behav 6:24-31. CrossRef Medline

Gruart A, Muñoz MD, Delgado-García JM (2006) Involvement of the CA3CA1 synapse in the acquisition of associative learning in behaving mice. J Neurosci 26:1077-1087. CrossRef Medline

Heise KF, Niehoff M, Feldheim JF, Liuzzi G, Gerloff C, Hummel FC (2014) Differential behavioral and physiological effects of anodal transcranial direct current stimulation in healthy adults of younger and older age. Front Aging Neurosci 6:146. CrossRef Medline

Hoy KE, Emonson MR, Arnold SL, Thomson RH, Daskalakis ZJ, Fitzgerald PB (2013) Testing the limits: investigating the effect of tDCS dose on working memory enhancement in healthy controls. Neuropsychologia 51:1777-1784. CrossRef Medline

Izquierdo I (1994) Pharmacological evidence for a role of long-term potentiation in memory. FASEB J 8:1139-1145. Medline

Jeon SY, Han SJ (2012) Improvement of the working memory and naming by transcranial direct current stimulation. Ann Rehabil Med 36:585-595. CrossRef Medline

Jiang T, Xu RX, Zhang AW, Di W, Xiao ZJ, Miao JY, Luo N, Fang YN (2012) Effects of transcranial direct current stimulation on hemichannel pannexin- 1 and neural plasticity in rat model of cerebral infarction. Neuroscience 226:421-426. CrossRef Medline

Jo JM, Kim YH, Ko MH, Ohn SH, Joen B, Lee KH (2009) Enhancing the working memory of stroke patients using tDCS. Am J Phys Med Rehabil 88:404-409. CrossRef Medline

Kabakov AY, Muller PA, Pascual-Leone A, Jensen FE, Rotenberg A (2012) Contribution of axonal orientation to pathway-dependent modulation of 
excitatory transmission by direct current stimulation in isolated rat hippocampus. J Neurophysiol 107:1881-1889. CrossRef Medline

Katz B, Miledi R (1968) The role of calcium in neuromuscular facilitation. J Physiol 195:481-492. CrossRef Medline

LiebetanzD, Nitsche MA, Tergau F, Paulus W (2002) Pharmacological approach to the mechanisms of transcranial DC-stimulation-induced after-effects of human motor cortex excitability. Brain 125:2238-2247. CrossRef Medline

Loo CK, Alonzo A, Martin D, Mitchell PB, GalvezV, Sachdev P (2012) Transcranial direct current stimulation for depression: 3 -week, randomised, sham-controlled trial. Br J Psychiatry 200:52-59. CrossRef Medline

Madroñal N, Gruart A, Delgado-García JM (2009) Differing presynaptic contributions to LTP and associative learning in behaving mice. Front Behav Neurosci 3:7. CrossRef Medline

Márquez-Ruiz J, Leal-Campanario R, Sánchez-Campusano R, MolaeeArdekani B, Wendling F, Miranda PC, Ruffini G, Gruart A, DelgadoGarcía JM (2012) Transcranial direct-current stimulation modulates synaptic mechanisms involved in associative learning in behaving rabbits. Proc Natl Acad Sci U S A 109:6710-6715. CrossRef Medline

Marshall L, Mölle M, Hallschmid M, Born J (2004) Transcranial direct current stimulation during sleep improves declarative memory. J Neurosci 24:9985-9992. CrossRef Medline

Martin DM, Liu R, Alonzo A, Green M, Loo CK (2014) Use of transcranial direct current stimulation (tDCS) to enhance cognitive training: effect of timing of stimulation. Exp Brain Res 232:3345-3351. CrossRef Medline

Mikula S, Trotts I, Stone JM, Jones EG (2007) Internet-enabled highresolution brain mapping and virtual microscopy. Neuroimage 35:9-15. CrossRef Medline

Monte-Silva K, Kuo MF, Hessenthaler S, Fresnoza S, Liebetanz D, Paulus W, Nitsche MA (2013) Induction of late LTP-like plasticity in the human motor cortex by repeated non-invasive brain stimulation. Brain Stimul 6:424-432. CrossRef Medline

Murray LM, Edwards DJ, Ruffini G, Labar D, Stampas A, Pascual-Leone A, Cortes M (2015) Intensity dependent effects of tDCS on corticospinal excitability in chronic spinal cord injury. Arch Phys Med Rehabil 96: S114-S121. CrossRef Medline

Neves G, Cooke SF, Bliss TV (2008) Synaptic plasticity, memory and the hippocampus: a neural network approach to causality. Nat Rev Neurosci 9:65-75. CrossRef Medline

Nitsche MA, Paulus W (2000) Excitability changes induced in the human motor cortex by weak transcranial direct current stimulation. J Physiol 527 3:633-639.

Nitsche MA, Paulus W (2001) Sustained excitability elevations induced by transcranial DC motor cortex stimulation in humans. Neurology 57: 1899-1901. CrossRef Medline

Nitsche MA, Fricke K, Henschke U, Schlitterlau A, Liebetanz D, Lang N,
Henning S, Tergau F, Paulus W (2003) Pharmacological modulation of cortical excitability shifts induced by transcranial direct current stimulation in humans. J Physiol 553:293-301. CrossRef Medline

Nitsche MA, Cohen LG, Wassermann EM, Priori A, Lang N, Antal A, Paulus W, Hummel F, Boggio PS, Fregni F, Pascual-Leone A (2008) Transcranial direct current stimulation: state of the art 2008. Brain Stimul 1:206223. CrossRef Medline

Pérez-Cadahía B, Drobic B, Davie JR (2011) Activation and function of immediate-early genes in the nervous system. Biochem Cell Biol 89: 61-73. CrossRef Medline

Ranieri F, Podda MV, Riccardi E, Frisullo G, Dileone M, Profice P, Pilato F, Di Lazzaro V, Grassi C (2012) Modulation of LTP at rat hippocampal CA3CA1 synapses by direct current stimulation. J Neurophysiol 107:18681880. CrossRef Medline

Reato D, Bikson M, Parra LC (2015) Lasting modulation of in-vitro oscillatory activity with weak direct current stimulation. J Neurophysiol 113: 1334-1341. Medline

Romero Lauro LJ, Rosanova M, Mattavelli G, Convento S, Pisoni A, Opitz A, Bolognini B, Valler G (2014) TCDS increases cortical excitability: direct evidence from TMS-EEG. Cortex 58:99-111. CrossRef Medline

Saunders N, Downham R, Turman B, Kropotov J, Clark R, Yumash R, Szatmary A (2015) Working memory training with tDCS improves behavioral and neurophysiological symptoms in pilot group with post-traumatic stress disorder (PTSD) and with poor working memory. Neurocase 21:271-278. Medline

Silver RA, Lubke J, Sakmann B, Feldmeyer D (2003) High-probability uniquantal transmission at excitatory transmission in barrel cortex. Science 302:1981-1984. CrossRef Medline

Stagg CJ, Nitsche MA (2011) Physiological basis of transcranial direct current stimulation. Neuroscientist 17:37-53. CrossRef Medline

Terzuolo CA, Bullock TH (1956) Measurement of imposed voltage gradient adequate to modulate neuronal firing. Proc Natl Acad Sci U S A 42:687694. CrossRef Medline

Thomson AM (2000) Facilitation, augmentation and potentiation at central synapses. Trends Neurosci 23:305-312. CrossRef Medline

Whitlock JR, Heynen AJ, Shuler MG, Bear MF (2006) Learning induces long-term potentiation in the hippocampus. Science 313:1093-1097. CrossRef Medline

Yu SH, Park SD, Sim KC (2014) The effect of tDCS on cognition and neurologic recovery of rats with Alzheimer's disease. J Phys Ther Sci 26:247249. CrossRef Medline

Zucker RS (1989) Short-term synaptic plasticity. Annu Rev Neurosci 12: 13-31. CrossRef Medline

Zucker RS, Regehr WG (2002) Short-term synaptic plasticity. Annu Rev Physiol 64:355-405. CrossRef Medline 